\title{
HOW TRADE-RESTRICTIVE IS STANDARDISED PACKAGING? ECONOMIC AND LEGAL IMPLICATIONS OF THE WTO PANEL REPORTS IN AUSTRALIA - TOBACCO PLAIN PACKAGING.
}

\begin{abstract}
KRISTY BUZARD.$^{\dagger}$ AND TANIA VOON $\stackrel{+}{\dagger}$
[The lengthy and long-awaited WTO Panel Reports in Australia-Tobacco Plain Packaging contain a host of material for reflection, particularly in relation to the Agreement on Technical Barriers to Trade (TBT) and the Agreement on Trade-Related Aspects of Intellectual Property Rights. While two of the Panel Reports proceed to appeal, we consider with respect to the two adopted Panel Reports the Panel's reasoning in relation to Article 2.2 of the TBT, focusing on the meaning of trade-restrictiveness. This concept central to WTO law has been under-examined to date, and these Panel Reports demonstrate some of the complexities in identifying trade-restrictive measures, particularly where they are non-discriminatory. The Panel found that Australia's measures restrict trade because they contribute to their objective of reducing tobacco consumption. Therefore, any equally effective alternative will similarly restrict trade. This curious result under TBT Article 2.2 may be particular to non-discriminatory measures that target 'socially bad' products such as tobacco.]
\end{abstract}

[Whether a measure restricts trade is a central question to many WTO provisions yet is underexplored in WTO caselaw to date. The long WTO Panel Reports in Australia - Tobacco Plain Packaging addresses this question among many others falling under the Agreement on Technical Barriers to Trade (TBT) and the Agreement on Trade-Related Aspects of Intellectual Property Rights. We investigate the meaning of trade-restrictiveness under TBT and its application to Australia's tobacco plain packaging measures. According to the Panel, a Member's measure restricts trade if it has a limiting effect on trade with one or more other Members. It found that description met by the Australian measures because they are designed to reduce consumption of tobacco products. Thus, any reasonably available alternative that is similarly effective in reducing consumption will restrict trade to at least the same degree. The Panel's

\footnotetext{
* We thank the hosts of and participants in the WTO Case Law Project conference held at the European University Institute in Florence in July 2019. This article contains our views as academics and does not necessarily reflect those of any employer or other entity. Any errors or omissions are ours.

$\dagger$ Associate Professor, Maxwell School, Syracuse University. Email: kbuzard@syr.edu.

* Professor, Melbourne Law School, University of Melbourne; PhD (Cantab); LLM (Harv); Dip Intl Law, LLB (Hons), BSc (Melb); AMusA. Email: <tania.voon@unimelb.edu.au>. Parts of this article arise from independent research funded by the Australian Research Council pursuant to the Linkage Project scheme (Project ID LP120200028). I have previously advised government departments and NGOs on tobacco plain packaging and related issues.
} 
reasoning may hold under TBT Article 2.2 for any non-discriminatory measure designed to limit a socially undesirable product such as tobacco.]

Keywords: Australia; international trade; labelling; tobacco; trade barriers; World Trade Organization

\section{Table of Contents}

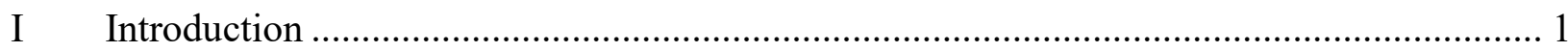

II The WTO Panel Reports in the Context of Public Health..................................................... 2

III Trade-Restrictiveness of Australia's Tobacco Plain Packaging: Relational Analysis .......... 4

A Meaning of Trade-Restrictiveness: A Limiting Effect on International Trade............ 5

B Trade Impact of Australia's Tobacco Plain Packaging Measures ............................... 6

C The Panel's Conclusion That Australia's Measures Are Trade-Restrictive ................ 9

IV Less Trade-Restrictive Alternatives to Australia's Tobacco Plain Packaging: Comparative Analysis .............................................................................................. 9

A Trade-Restrictiveness of the Proposed Alternatives .................................................. 10

B Contribution of the Proposed Alternatives to Australia's Objective .......................... 12

$\mathrm{V} \quad$ Weighing and Balancing under the TBT, TRIPS and Other WTO Agreements................... 15

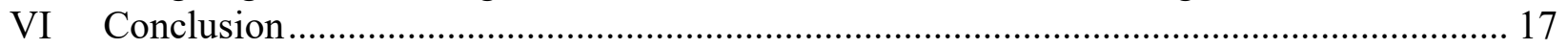




\section{INTRODUCTION}

On 28 June 2018, the Panel circulated its Reports on complaints brought by Cuba, the Dominican Republic, Honduras and Indonesia against Australia's standardised ("plain”) tobacco packaging scheme. ${ }^{1}$ For Cuba and Indonesia, these Reports represent the end of an unusually long saga that began with requests for consultations in 2013. This article focuses on the Panel Reports with respect to those two complaints, ${ }^{2}$ which now have legal force following their adoption by the WTO Dispute Settlement Body. For the Dominican Republic and Honduras, the saga continues following the appeals by those two countries. A fifth WTO Member, Ukraine, was the first to launch a WTO dispute against Australia regarding the same measure, but Ukraine later requested the Panel to suspend its proceedings, and the Panel's authority with respect to Ukraine lapsed in 2016. The significance of these disputes is exemplified by the record numbers of third parties they attracted.

Australia's measure prohibits all promotional colours and logos on tobacco packages, allowing only the brand name and variant in a standardised font, size and colour, with the rest of the package taken up by graphic and textual health warnings and a drab dark brown colour. The Panel dismissed all claims, finding Australia's measure consistent with WTO law.

The main claims by Cuba and Indonesia were brought under Article 2.2 of the Agreement on Technical Barriers to Trade (TBT) and under various provisions of the Agreement on TradeRelated Aspects of Intellectual Property Rights (TRIPS): Articles 15.4, 16.1, 16.3, 20, 22.2(b), and 24.3, as well as Article 10bis of the Paris Convention for the Protection of Industrial Property read with TRIPS Article 2.1 and (particularly for Cuba) Article 6quinquies of the Paris Convention read with TRIPS Article 2. Several aspects of the Panel Reports addressed TRIPS provisions not previously subject to WTO jurisprudence. However, in view of space constraints we focus here on the Panel's analysis of TBT Article 2.2, which has significant systemic implications for WTO dispute settlement. Specifically, we investigate the under-explored concept of traderestrictiveness $^{3}$ and the availability of trade-restrictive alternatives as reflected in the Panel Reports. The Panel relied on some of this analysis in its subsequent TRIPS findings. We note that the complainants abandoned (by presenting no arguments on) their claims of discrimination under TBT Article 2.1 and the General Agreement on Tariffs and Trade 1994 (GATT) Article III:4. ${ }^{4}$

As in many high-income countries, smoking prevalence in Australia is low and declining. The $12 \%$ of the population who were daily smokers in 2016 consumed just over 14 billion cigarette sticks, along with additional small quantities of cigars, cigarillos and roll-your-own tobacco.

\footnotetext{
${ }^{1}$ Tobacco Plain Packaging Act 2011 (Cth); Tobacco Plain Packaging Regulations 2011 (Cth).

2 Panel Reports, Australia - Certain Measures Concerning Trademarks, Geographical Indications and Other Plain Packaging Requirements Applicable to Tobacco Products and Packaging (Australia - Tobacco Plain Packaging), WT/DS458/R, WT/DS457/R (circulated 28 June 2018, adopted 27 August 2018).

${ }^{3}$ See Voon (2015).

${ }^{4}$ Panel Reports, Australia - Tobacco Plain Packaging, para. 8.2.
} 
Cigarette retail sales in Australia totalled $\$ 14.5$ billion of the total tobacco product sales of $\$ 17.3$ billion (Scollo and Bayly 2019b). By 2016, all tobacco products were imported, so that the Australian tobacco industry was almost entirely in wholesale operations. Three foreign-owned multinational companies control over $80 \%$ of the wholesale market (Scollo and Bayly 2019a).

To put the size of the Australian market into perspective, the global cigarette market saw retail sales of roughly $\$ 700$ billion and 5.5 trillion sticks in 2016 (Campaign for Tobacco Free Kids, 2018). That is, the Australian market is mature, declining, and very small in the global context. It is therefore widely believed that Australia's tobacco control measures are being challenged not primarily to maintain access to the Australian market, but in an attempt to discourage future adoption of similar measures in other markets. This is one sense in which the outcome of this case can be expected to have important ramifications.

In this article, we first set out in Part II the broader context of the Panel Reports in terms of the surrounding public health environment and their relevance for public health. In Part III, we address the Panel's analysis first of what trade-restrictiveness means in Article 2.2 of the TBT (as part of the so-called 'relational' analysis) and second of whether the Australian measures are traderestrictive within that definition. Having concluded that the measures do restrict trade, the Panel went on to consider the existence of reasonably available less trade-restrictive alternatives that would make an equivalent contribution to Australia's objective (the so-called comparative analysis). We consider the Panel's analysis in this regard in Part IV. We then go on in Part V to highlight the different types of 'weighing and balancing' that a panel might need to undertake under the TBT or TRIPS or other WTO agreements, noting that the relevant WTO provisions allowing this kind of reasoning contain different language and ultimately set up distinct tests.

In conclusion, we note how the Panel's finding that the measures restrict trade by contributing to the objective of reducing the use of and exposure to tobacco products made it difficult for the complainants to identify any alternative that would be equally effective in this regard while restricting trade to a smaller degree. This outcome may mean that TBT Article 2.2 has a different significance for non-discriminatory measures that are designed to reduce consumption of a particular undesirable product for non-trade reasons such as promoting public health or preserving the environment. Particularly where such products are largely or wholly imported, an effective measure of this kind is likely to restrict trade to the extent necessary to achieve its objective. The core of such a dispute may therefore be, as was the case here, on whether the measure is in fact effective in contributing to its non-trade objective.

\section{The WTO Panel Reports in the Context of Public Health}

These WTO Panel Reports form part of a much broader stand-off between the tobacco industry and public health, which has increasingly strayed into matters of international law, including in the context of international economic law. In 2005, the WHO Framework Convention on Tobacco Control (FCTC) entered into force; it now has 181 parties, in comparison to the WTO's 164 
Members (with most FCTC parties being WTO Members and vice versa). The FCTC has reshaped the governance of tobacco control on a global scale and contributed significantly to the defence of tobacco control measures against legal challenges. ${ }^{5}$

Tobacco has long featured in WTO dispute settlement, as well as under the General Agreement on Tariffs and Trade 1947. However, most of these disputes have focused not directly and primarily on health objectives but on other matters such as customs and taxation. ${ }^{6}$ Health played a bigger role in the complaint brought by the United States against Thailand ${ }^{7}$ under the GATT 1947 and the WTO complaint brought by Indonesia against the United States. ${ }^{8}$ In the latter case, the Panel took account of the FCTC at several points in assessing the health implications of both the United States' ban on flavoured cigarettes including clove and the ban's exclusion of menthol cigarettes, ${ }^{9}$ even though the United States is merely a signatory to the FCTC and Indonesia is neither a signatory nor a party.

Tobacco control measures have also been challenged in investment treaty arbitration, including in unsuccessful claims brought by Philip Morris against Uruguay ${ }_{.}^{10}$ and Australia.. ${ }^{11}$ Australia's tobacco plain packaging scheme has thus been challenged in at least three different legal forums: in the WTO, under the bilateral investment treaty between Australia and Hong Kong, and (again unsuccessfully) under the Australian Constitution. ${ }^{12}$ These ongoing challenges reflect the importance of this dispute, not only to Australia but to countries around the world, several of which have now implemented or are considering standardised tobacco packaging. The World Health Organization and FCTC Secretariat therefore submitted amicus curiae briefs in both international challenges to Australia's measure, and the tobacco industry openly supported the WTO complainants.

In economic terms, there is now broad agreement in public health circles that the consumption of tobacco products reduces social welfare through multiple channels. While there may be heterogeneity on the individual level, this commodity is clearly a bad as opposed to a good in terms of social welfare. Australia argued in its written submission to the Panel that tobacco is "the only legal consumer product that kills half of its long-term users when used exactly as intended by

\footnotetext{
${ }^{5}$ Zhou and Liberman (2018); Zhou et al (2018).

${ }^{6}$ See, eg, Appellate Body Report, Thailand - Customs and Fiscal Measures on Cigarettes from the Philippines, WT/DS371/AB/R (17 June 2011); Appellate Body Report, Dominican Republic - Measures Affecting the Importation and Internal Sale of Cigarettes, WT/DS302/AB/R (25 April 2005); GATT Panel Report, United States - Measures Affecting the Importation, Internal Sale and Use of Tobacco, DS44/R (12 August 1994).

${ }^{7}$ GATT Panel Report, Thailand - Restrictions on Importation and Internal Taxes on Cigarettes, DS10/R-37S/200 (5 October 1990).

${ }^{8}$ Appellate Body Report, United States-Measures Affecting the Production and Sale of Clove Cigarettes (US-Clove Cigarettes), WT/DS406/AB/R (4 April 2012).

${ }^{9}$ Panel Report, US - Clove Cigarettes, WT/DS406/R (2 September 2011) paras. 7.231, 7.414.

${ }^{10}$ Philip Morris Brands Sàrl et al v Uruguay, ICSID Case No ARB/10/7, Award (8 July 2016).

${ }^{11}$ Philip Morris Asia Ltd v Australia, PCA Case No 2012-12, Award on Jurisdiction and Admissibility (17 December 2015).

12 JT International SA v Australia; British American Tobacco Australasia Ltdv Australia (2012) 250 CLR 1.
} 
the manufacturer." 13 The overwhelming consensus around the need for tobacco control that is demonstrated by the fact that 181 countries are party to the FCTC is important context for the Panel's reasoning regarding Australia's tobacco plain packaging scheme. Some aspects of that reasoning may not be fully generalizable to other commodities that do not present such clear threats to such an important objective as protecting human health.

Before turning to the Panel's reasoning about trade-restrictiveness and less trade-restrictive alternatives, we highlight certain factual findings made by the Panel with respect to Australia's contested measures. These measures operate against the backdrop of the FCTC, which the Australian legislation explicitly names among its objectives, which are: "(a) to improve public health" (for example by discouraging smoking initiation, encouraging cessation, and reducing exposure to smoke) and "(b) to give effect to certain obligations that Australia has" as an FCTC party (Article 3(1)). The Panel relied on the FCTC at several points in its reports, again notwithstanding the fact that Indonesia is neither party nor signatory to the FCTC and Cuba is but a signatory. (In contrast, one of the appellants, Honduras, is an FCTC party.)

One of the guiding principles of the FCTC is that "[e]very person should be informed of the health consequences, addictive nature and mortal threat posed by tobacco consumption and exposure to tobacco smoke" (Article 4.1). The Panel recognised that "the images and messages conveyed by tobacco packaging are of such a nature as to be capable of conveying a belief that initiating tobacco use can fulfil certain needs, and that youth and young adults are particularly vulnerable to acting on compulsions that are caused by those needs" (para. 7.1456). Australia's plain packaging measures act against such messages because, according to the Panel, they are "apt to reduce the appeal of tobacco products, enhance the effectiveness of [graphic health warnings] and reduce the ability of the retail packaging of tobacco products to mislead consumers about the harmful effects of smoking or using tobacco products, and, as a consequence, have an impact on smoking behaviours" (para. 7.1456).

\section{Trade-Restrictiveness of Australia’s Tobacco Plain Packaging: Relational}

\section{ANALYSIS}

Having found that Australia's challenged measures constitute a technical regulation under the TBT, the Panel had to assess the complainants' claims that these measures breach Article 2.2 of the TBT, which requires WTO Members to:

ensure that technical regulations are not prepared, adopted or applied with a view to or with the effect of creating unnecessary obstacles to international trade. For this purpose, technical regulations shall not be more trade-restrictive than necessary to fulfil a legitimate objective, taking account of the risks non-fulfilment would create. Such legitimate objectives are, inter alia: ... protection of human health ...

\footnotetext{
${ }^{13}$ Panel Reports, Australia - Tobacco Plain Packaging, para. 7.1298.
} 
In its assessment under Article 2.2, the Panel found that the legitimate objective of the measures was "to improve public health by reducing the use of, and exposure to, tobacco products" (paras. $7.232,7.251)$.

Relying on previous reasoning by the WTO Appellate Body, the Panel found that Article 2.2 first requires a "relational analysis" of three factors: the degree to which the measure contributes to the legitimate objective; the measure's trade-restrictiveness; and the nature of the risks at issue and the gravity of consequences of non-fulfilment of the relevant objective (para. 7.31). In most cases, a subsequent "comparative analysis" is also required: comparing the first two of these factors with reasonably available less trade-restrictive alternatives, taking account of the risks of non-fulfilment (para. 7.32). Here in part III we focus on the trade-restrictiveness of the measure, for the purposes of the relational analysis, while below in part IV we focus on alternatives, for the purposes of the comparative analysis. In concluding that the measures do not breach Article 2.2, the Panel also found that the measures make a meaningful contribution to their objective and that the consequences of non-fulfilment of that objective are 'particularly grave' (para. 7.1725).

\section{A Meaning of Trade-Restrictiveness: A Limiting Effect on International Trade}

The Panel indicated that a measure that neither explicitly restricts nor allegedly discriminates against imports may still be trade-restrictive, in the sense of having a limiting effect on international trade. That effect may be demonstrated by qualitative or quantitative arguments or evidence, "including evidence relating to the characteristics of the challenged measure as revealed by its design and operation" (para. 7.1076).

The Panel rejected Australia's submission that the relevant effects are the effects on trade with all WTO Members, rather than just the complainant(s). In doing so, the Panel considered as relevant context for interpreting Article 2.2 the reference in Article 2.9 to a technical regulation having "a significant effect on trade of other Members". Moreover, the Panel implied that a 1995 recommendation by the TBT Committee indicating that those words refer to the effect on trade "between two or more Members". ${ }^{14}$ constitutes a subsequent agreement. ${ }^{15}$ with respect to the interpretation of Article 2.9 and "should therefore inform, as relevant, our understanding of the relevant context provided by Article 2.9” (para. 7.1085).

A different conclusion on this interpretative question would have required the Panel to focus on the impact of the challenged measures on trade with all Members rather than their impact on trade with the complainants. However, what is surprising is how difficult it is to link the Panel's finding on this question with the evidence and analysis of trade volumes and value. Despite finding that the relevant trade to examine is the complainants' trade with Australia, very little of the evidence before the Panel or its analysis concerned the complainants' trade specifically. The Panel simply

\footnotetext{
${ }^{14}$ Committee on Technical Barriers to Trade, Secretariat Note: Decisions and Recommendations Adopted by the WTO Committee on Technical Barriers to Trade Since 1 January 1995, G/TBT/1/Rev.12 (21 January 2015) s. 4.3.1.1, p. 20.

${ }^{15}$ Vienna Convention on the Law of Treaties, Article 31(3)(a).
} 
found that by reducing the use of tobacco products the measures reduce the volume (but not value) of tobacco product imports from all sources (para. 7.1255). The absence of more specific analysis with respect to the complainants' trade may have arisen from a dearth of data, given that the sales volumes presented are not differentiated by country of origin. Most of the evidence in the relevant appendices concern instead Australian consumption. ${ }^{16}$

In the Panel's estimation, Australia's interpretation that the relevant effects are the effects on trade with all WTO Members would "diminish the rights of Members under Article 2.2." ${ }^{17}$ Yet Australia's position may make sense in some cases from the point of view of the larger objective of liberalizing trade, which is arguably relevant as a component of the object and purpose of the WTO agreements, pursuant to Article 31(1) of the Vienna Convention on the Law of Treaties (VCLT). Imagine the following scenario for argument's sake: there is a change in a WTO Member's domestic regulation that leads to a dramatic increase in its imports, while reducing imports from one member by a small amount. Ignoring the effects on trade with all WTO Members would lead to a situation where the regulation may be deemed incompatible with the TBT, and its removal would roll back trade liberalization in order to preserve the rights of one Member. While perhaps extreme to make a point, this scenario is not far-fetched, as the direction of impact for very few regulations will be the same for all Members. Regulations are the rules of the trading game, and they tend to tilt the playing field.

\section{B Trade Impact of Australia's Tobacco Plain Packaging Measures}

The complainants maintained that the challenged measures are trade-restrictive because they both alter the competitive environment of producers (i.e. tilt the playing field) and have a limiting effect on the volume and value of the complainants' trade. They also argued that the challenged measures impose conditions on sales that entail compliance costs. We focus on the first and second of these arguments because they were the focus of the Panel's reasoning in concluding that the measures are trade-restrictive.

In $U S-C O O L,{ }^{18}$ the Panel stated that the effect of the measures on competitive opportunities should be the focus of the trade-restrictiveness analysis. On appeal, the Appellate Body reversed the Panel's finding that the United States' measure was inconsistent with TBT Article 2.2 but was unable to complete the legal analysis to determine its consistency with that provision.. ${ }^{19}$ The Appellate Body did not disturb the Panel's findings on the relevance of competitive opportunities because of the way the appeal was argued..$^{20}$ More recently, the Appellate Body in the US-COOL

\footnotetext{
${ }^{16}$ Appendix D4 contains some suggestive trade data on cigars, but the Panel's conclusions are not based on the cigar market.

${ }^{17}$ Panel Reports, Australia - Tobacco Plain Packaging, para. 7.1078.

18 Panel Reports, United States - Certain Country of Origin Labelling (COOL) Requirements (US - COOL), WT/DS384/R, WT/DS386/R (circulated 18 November 2011, adopted 23 July 2012).

${ }^{19}$ Appellate Body Reports, US - COOL, WT/DS384/AB/R, WT/DS386/AB/R (circulated 29 June 2012, adopted 23 July 2012) para. 491.

${ }^{20}$ Appellate Body Reports, US - COOL, para. 381.
} 
compliance proceedings focused on competitive opportunities more with respect to TBT Article 2.1 than Article 2.2. However, the Appellate Body explicitly stated that trade-restrictiveness under TBT Article 2.2 could be shown by "a limiting effect on competitive opportunities in qualitative terms" (particularly in relation to de jure discriminatory measures) or "evidence ... of actual trade effects" (particularly in relation to "non-discriminatory internal measures").. ${ }^{21}$

In Australia - Tobacco Plain Packaging, the complainants relied heavily on arguments related to the competitive environment, while Australia disagreed that these arguments were relevant. The Panel resolved this in favour of the complainants, in that it examined the effects of the measures on competitive opportunities as well as on the value and volume of trade. However, the Panel found persuasive evidence only with respect to trade volumes, stating that the measures "contributed to a reduction of the volume of imports of premium tobacco products" both relative to low-priced products and absolutely (para. 7.1196). The Panel did not accept the complainants' suggestion that these decreases were caused solely by "downtrading" from premium to nonpremium products. Instead, at least in part, the absolute decrease arose from an overall diminution in the consumption of tobacco products (in a domestic market now supplied entirely by imports), ${ }^{22}$ and the relative decrease arose also in part from the evolution of higher- and lower-priced market segments even before the measures were implemented (para. 7.1197).

Several points in this reasoning warrant further discussion. First, the Panel accepted that there was econometric evidence, albeit limited, that the tobacco plain packaging measures contributed to the overall reduction in consumption of tobacco products. At the same time, the Panel acknowledged that these impacts were a combination of the tobacco plain packaging measures and the enlarged graphic health warnings that went into effect at the same time (para. 7.1205). No method has been found to empirically disentangle the two effects. We therefore must rely on theoretical arguments to understand the possibilities and associated reasoning.

It is entirely possible that the reduction in overall consumption-which saw consumption of both low- and high-priced segments decline, with a larger decline for the high-priced segmentcomprises effects of both (i) larger graphic health warnings and (ii) plain packaging requirements leading to downtrading. If the effect of the graphic health warnings is large and of roughly the same magnitude across the two segments, while the downtrading effect is smaller than this magnitude, we arrive at the observed outcome. But suppose, alternatively, that the negative effect of the graphic health warnings on consumption is larger for the high-priced than the low-priced segment. This could easily be the case if, for instance, consumers of high-priced tobacco products value their health more highly or have greater access to cessation programs. Then we could observe the same effect on overall consumption with absolutely no effect from the plain packaging

\footnotetext{
${ }^{21}$ Appellate Body Reports, US - COOL - Recourse to Article 21.5 of the DSU by Canada and Mexico (US - COOL (Article 21.5 - Canada and Mexico)), WT/DS384/AB/RW, WT/DS386/AB/RW (circulated 18 May 2015, adopted 29 May 2015) para. 5.208, n 643.

${ }^{22}$ Panel Reports, Australia - Tobacco Plain Packaging, para. 7.1207.
} 
requirements. Both of these possibilities seem plausible, and we next turn to a discussion of some facts in the case that make distinguishing between the two possibilities more difficult.

The conclusion that the plain packaging requirements led to downtrading via an alteration to the competitive environment was not obvious. The complainants argued that "Competition in the market is distorted by differentially harming producers of premium brands and brands that cater to specific customer preferences relative to producers of low quality cigarettes that mainly compete on price." ${ }^{23}$ While Australia explicitly stated that the intent of the plain packaging regulations was to reduce the ability of tobacco producers to differentiate their products, ${ }^{24}$ and there was both a relative and absolute reduction in the consumption of high-priced cigarettes, it's not clear that the "downtrading" observed in the data arose from the plain packaging requirements.

A major issue is that, although the complainants argued that reduced ability to differentiate products should lead to more price competition and reduced prices (para. 7.1169), not only did prices (even net of taxes) increase, but the quality premium also increased. That is, high-priced cigarettes saw a larger net price increase than did low-price brands (para. 7.1215). In fact, the prices went up enough to compensate for the reduced volume in the high-quality market so that total value of sales increased (para. 7.1211). This is why the Panel's ruling that the measures were trade-restrictive rested on a reduction in trade volumes alone.

Without having the producers' cost data, one can't say for sure whether prices net of both taxes and cost rose or fell (7.1181). However, since both the observed price and quantity moved in the opposite direction of that predicted by decreased brand differentiation, it seems unlikely that producers have suffered from increased price competition due to an inability to differentiate their brands. There are plausible alternative explanations. For instance, if other components of Australia's tobacco control policy have reduced demand even uniformly across both market segments, this may push the producers of high-quality brands into a portion of their demand curves where consumers are very insensitive to price (i.e. where demand is inelastic), allowing producers to increase prices more than would be expected for the reductions in demand. This may be a shortrun phenomenon in which previous investments in branding will be effective under plain packaging for some period of time. An alternative, but closely related, possibility is that even without demand reductions coming through other channels, producers may have reacted to reduced ability to differentiate their brands by increasing prices on those consumers who are sufficiently brand loyal to be unaffected by plain packaging. Yet another possibility is that producers are reacting to a reduced ability to differentiate through branding by using higher prices as a means to signal higher quality.

This rather unexpected configuration of the data was sufficient for the Panel to reject the complainants' argument that the tobacco plain packaging measures had restricted trade by

\footnotetext{
${ }^{23}$ Panel Reports, Australia - Tobacco Plain Packaging, para. 7.1101.

${ }^{24}$ Panel Reports, Australia - Tobacco Plain Packaging, para. 7.1191.
} 
restructuring the competitive conditions of the market. The Panel did not directly refute that the measures had affected the competitive environment, but rather argued that the complainants had failed to show how any effects on the competitive environment restricted international trade (paras. 7.1166, 7.1168).

\section{The Panel's Conclusion That Australia's Measures Are Trade-Restrictive}

The Panel concluded that the measures are trade-restrictive "insofar as, by reducing the use of tobacco products, they reduce the volume of imported tobacco products on the Australian market, and thereby have a 'limiting effect' on trade" (para. 7.1208). Surprisingly, the Panel's finding that the measures are trade-restrictive thus relied directly on its finding that the measures contribute to their legitimate objective of reducing the appeal of tobacco products (para. 7.1206). Given the nature of the product, that is, as a social "bad", it is hard to refute this logic. The legitimate objective of the tobacco plain packaging measures is to "reduce the use of ... tobacco products." 25 As all tobacco products in Australia are imported, if the measures contribute to this objective, they must restrict the volume of trade.

This conclusion may seem counterintuitive and is concerning from the perspective of public health. However, it is of course not the end of the analysis. Just as a provisional finding of a GATT violation could still be averted through the use of the general exceptions in GATT Article XX, under the TBT a measure's trade-restrictiveness per se may be WTO-consistent. A WTO breach would arise only if the measure is more trade-restrictive than necessary to fulfil a legitimate objective. In the next section we consider an important part of that subsequent analysis as applied in this dispute: the availability to Australia of less trade-restrictive alternatives to plain packaging that could make an equivalent contribution to its health objectives.

\section{Less Trade-Restrictive Alternatives to Australia's Tobacco Plain Packaging: COMPARATIVE ANALYSIS}

The Panel considered four alternatives proposed by the complainants: an increase in the minimum legal purchasing age (MLPA) from 18 to 21 years; an increase in taxation of tobacco products; enhanced social marketing campaigns; and a "pre-vetting" mechanism under which each package would have to be approved before being placed on the market. Relying on Appellate Body reasoning, ${ }^{26}$ the Panel identified the burden as falling on the complainants to identify possible alternatives and then on the respondent to rebut the complainants' prima facie case by showing that the alternatives proposed are not reasonably available or less trade-restrictive, or that they do not make an equivalent contribution to the respondent's legitimate objective (para. 7.1363). For various reasons, the Panel did not accept that any of the proposed alternatives satisfy the criteria

\footnotetext{
${ }^{25}$ Panel Reports, Australia - Tobacco Plain Packaging, para. 7.232.

${ }^{26}$ Appellate Body Report, United States - Measures Concerning the Importation, Marketing and Sale of Tuna and Tuna Products ('US - Tuna II (Mexico)'), WT/DS381/AB/R (16 May 2012), para. 323.
} 
to demonstrate that Australia's measures are more trade-restrictive than necessary to achieve their legitimate objective (para. 7.1726). Therefore, the claims under TBT Article 2.2 failed.

We consider the four proposed alternatives in turn, focusing on the question of whether the proposed alternatives are less trade-restrictive than Australia's challenged measures. The Panel found none of these alternatives less trade-restrictive than the existing measures. We leave to one side several related issues, including Australia's largely unsuccessful argument that three of the four proposed alternatives are not true alternatives because they are measures that Australia essentially already implements.

\section{A Trade-Restrictiveness of the Proposed Alternatives}

The Panel found that increasing the MLPA to 21 years would, like the challenged Australian measures, "restrict the volume of trade by an amount commensurate with its contribution to Australia's objective" (para. 7.1414). While the Dominican Republic admitted that all the alternatives could make the same contribution toward Australia's objective (contingent on the Panel finding that the tobacco plain packaging measures have an impact in the first place), it argued that increasing the MLPA would be less trade-restrictive because an increase in the MLPA would not restrict competitive opportunities (para. 7.1338). However, as discussed in Section III, the Panel found that the trade-restrictiveness of the plain packaging measures via a change in the competitive environment was not demonstrated. Further, as Australia pointed out, all trade that relied on sales to consumers between 18 and 20 years of age would be restricted under this alternative. It seems mainly on the basis of these arguments that the Panel suggested that the evidence before it was insufficient to determine precisely the impact of this alternative on the volume or value of imports, in general or in particular price segments. With little discussion, the Panel said it was "not persuaded" by the complainants' assertion that this alternative would "necessarily be less trade-restrictive" and that it had "no reason to assume that such impact would be less than that observed in relation to" the challenged measures (para. 7.1416).

The Dominican Republic also argued that a "non-discriminatory age restriction" is "not a traderestrictive measure under" any WTO agreement (i.e. any associated "reduction in competitive opportunities ... is not protected by the covered agreements"), which is a "decisive" indication that this alternative is less trade-restrictive than plain packaging (para. 7.1406). The Panel did not explicitly address this argument in its analysis of the MLPA but addressed a similar argument by the Dominican Republic regarding the third alternative of improved social marketing campaigns.. ${ }^{27}$ There the Panel dismissed the argument, saying that this characterisation of the alternatives is not a "directly pertinent consideration in our assessment of the extent to which the proposed alternative measure would or would not be trade-restrictive. Rather, ... we must consider the extent to which it could be expected to have a limiting effect on international trade" (para. 7.1582). The Panel rightly thus chose to prioritize the economic and actual trade effects of the proposed alternatives

\footnotetext{
${ }^{27}$ The Dominican Republic made a similar argument regarding the second alternative (the excise tax) (para. 1485).
} 
over whether they might of themselves breach any WTO agreement, leaving to one side the question of whether the Dominican Republic was correct in that respect.

The Panel described the second proposed alternative as an increase in the excise tax on tobacco products. It agreed with the Dominican Republic that (in principle at least), in order to make an equivalent contribution to Australia's objective, the tax would have to be calibrated to reduce the overall consumption of tobacco products to the same extent as the plain packaging measures, such that "it would be equally trade-restrictive" in terms of trade volumes (paras. 7.1484, 7.1491). According to the Panel, an increase in tax would also not address the complainants' concerns about alleged "downtrading" as mentioned above or any related impact on the value of trade in tobacco products, as tax increases themselves have been shown to cause downtrading and other alterations to the conditions of competition (paras. 7.1493, 7.1494). It's important to recall that, even if the tax increase did address these concerns, the Panel was not convinced that the plain packaging measures have restricted trade via these channels (downtrading and impact on competitive conditions) and therefore would not consider this sufficient to declare the excise tax increase less trade-restrictive.

Let's look carefully, for a moment, at the idea that the excise tax increase would have to be calibrated to have exactly the same impact as the tobacco plain packaging measures. The Dominican Republic made the same argument in the case of the MLPA increase, arguing that if an increase in the MLPA to 21 would reduce consumption more than plain packaging and is therefore more trade-restrictive, the MLPA could instead be raised to 19 or 20 (para. 7.1396). Ignoring the difficulties in implementation, from the point of view of the legal requirements of TBT Article 2.2, this seems sensible. But from the point of view of policy making-especially when setting tax rates - there are many considerations that a policy maker might take into consideration, e.g. distributional impacts on different consumer groups created by the price increase, how the markets for other closely-related goods might be affected, the effect on the government budget, or long term plans for the tax schedule that might already be in place. Altering tax rates (or other policies) that presumably have already been carefully set to take into account a wide range of considerations for the express purpose of substituting another policy seems illadvised.

Turning to the third proposed alternative, the Panel found, in only a few sentences, that improved social marketing campaigns would not be less trade-restrictive than the challenged measures because to the extent that they would make an equivalent contribution to Australia's legitimate objective by reducing consumption of tobacco products, they would restrict trade to at least the same degree (para. 7.1583).

The Panel's analysis regarding trade-restrictiveness differed somewhat with respect to the fourth proposed alternative of pre-vetting of packages by a body such as the Australian Competition and Consumer Commission. The Panel suggested that such a system could be even more stringent than the existing Australian approach, for example if brand names and brand variants currently allowed 
were not approved for placing on the market. Pre-vetting could also impose "additional administrative and operational costs ... on industry participants" in connection with the additional layers of regulatory review (para. 7.1653). The Panel saw such costs as outweighing any possible reduction in trade-restrictiveness under a pre-vetting mechanism versus the challenged measures (para. 7.1654).

\section{B Contribution of the Proposed Alternatives to Australia's Objective}

After concluding that there was not enough evidence to show that any of the four alternatives was less trade-restrictive than the plain packaging measures, in each case the panel went on to consider whether the alternative would make an equivalent contribution to Australia's legitimate objective of reducing consumption of, and exposure to, tobacco products. Strikingly, the Panel also concluded that none of the four proposed alternatives would have an equivalent effect.

This is particularly interesting in light of the Panel's finding that none of the alternatives had been demonstrated to be less trade-restrictive than the tobacco plain packaging measures. Taken together with the Panel's reasoning as we highlighted in Section III-that is, that the plain packaging measures are trade-restrictive to the extent that they contribute to achieving Australia's goal of reducing consumption of tobacco products - this stance might at first appear puzzling. Let's take a deeper look, starting with the Panel's understanding of an "equivalent contribution."

The Panel referred to the ruling in the $U S-C O O L$ case to clarify that what matters in the analysis of equivalent contribution is "the overall degree of contribution that the technical regulation makes to the objective pursued ... rather than any individual isolated aspect or component of contribution" (para. 7.1368). It went on to elaborate that a proposed alternative measure may make an equivalent contribution in a different way than the measure under consideration (para. 7.1454), but at the same time it addressed the plain packaging measures in the context of Australia's comprehensive tobacco control policy.

Australia's tobacco control policy includes a wide range of measures, including some form of each of the first three proposed alternatives in this case (a minimum legal purchasing age, excise taxes, and social marketing strategies at multiple governmental levels). The Panel found that Australia's tobacco control policy is one, as in Brazil-Retreaded Tyres, in which "[s]ubstituting one element of this comprehensive policy for another would weaken the policy by reducing the synergies between its components". ${ }^{28}$ The Panel argued that when a policy is comprehensive and is specifically designed so that the component measures are complementary, the individual component measures are not necessarily substitutable. In econometric terms, the Panel was implying that there are interaction effects: each policy has its own individual effect, but there is an additional effect that comes from the two policies being in place simultaneously.

\footnotetext{
28 Panel Reports, Australia - Tobacco Plain Packaging, para. 7.1528, citing Appellate Body Report, Brazil Retreaded Tyres, para. 172.
} 
A closely-connected question is about the objective to which the alternatives are meant to contribute. In some parts of its reasoning, the Panel defined the objective broadly, as in the opening paragraph of its analysis of the MLPA increase to 21 years, as "improving public health by reducing the use of, and exposure to, tobacco products" (para. 7.1432). However, in paragraph 7.1386, for instance, in its analysis of whether less trade-restrictive alternatives are reasonably available to Australia, the Panel expanded on the broad objective by adding that the tobacco plain packaging (TPP) "measures seek to achieve this by reducing the appeal of tobacco products, increasing the effectiveness of GHWs and reducing the ability of the retail packaging of tobacco products to mislead consumers about the harmful effects of smoking or using tobacco products."

Requiring the proposed alternatives to make a contribution to the broad goal in precisely the same manner as the plain packaging measures seems to be in direct opposition to the general statement defining equivalent contribution in paragraph 7.1368 cited above. This apparent contradiction may be resolved by the features of this particular policy, that is, that it is comprehensive and complementary, as we explain below.

The Panel rejected arguments that an increase in the MLPA to 21 years could make an equivalent contribution, in part by highlighting the fact that the plain packaging measures are the only piece of the comprehensive strategy that would:

affect the design features of tobacco packaging that, as we have found, convey images and messages which are in turn capable of conveying a belief, in particular to adolescents and young adults, that initiating tobacco use can fulfil certain psychological needs and contribute to making tobacco products appealing. Adolescents would continue to be susceptible to those images and messages, and thus the compulsions to act on them, in an environment where branded packages were still available, including through non-commercial channels. In the absence of the TPP measures, this means of communication would not be addressed at all. ${ }^{29}$

The Panel went on to state that the current MLPA of 18 years combined with the plain packaging measures addresses tobacco use more comprehensively than would a higher MLPA alone, and that removing the plain packaging measures would weaken the synergies between the measures within the comprehensive policy (para. 7.1461). Thus, in deciding that an increase in the MLPA to 21 would not make a contribution equivalent to plain packaging, the Panel invoked both the argument that there is an interaction effect and the idea that the specific way in which plain packaging contributes to the overall goal is important.

As with the proposed alternative to increase the MLPA, the Panel agreed that increasing the excise tax on tobacco products could make a meaningful contribution (para. 7.1523), but again invoked both types of arguments in concluding that substituting an even higher excise tax for the plain packaging measures would not make an equivalent contribution. It found both that increasing excise taxes would "necessarily leave in place those aspects of tobacco product and retail

${ }^{29}$ Panel Reports, Australia - Tobacco Plain Packaging, para. 7.1459. 
packaging that the TPP measures address as "part of a more complex suite of measures directed at the same objective' of tobacco control" 30 and that the two types of policies have different causal pathways and so they can influence a broader range of tobacco users together than separately (para. 7.1505).

Regarding improved social marketing campaigns, the Panel did not provide reasons about differing causal pathways between this alternative and plain packaging, perhaps because there is more of an overlap in how these two policies work. However, as in the cases of the first two alternatives, the Panel invoked the synergies between the two policies to conclude that improved social marketing campaigns would not make an equivalent contribution on their own. In fact, it went so far as to conclude that social marketing campaigns in the absence of tobacco plain packaging could confront potential consumers with mixed messages (para. 7.1614). This conclusion is in line with Australia's argument that the plain packaging measures enhance the effectiveness of its current social marketing campaigns (para. 7.1591).

The Panel's reasoning regarding a pre-vetting mechanism was entirely different, as this policy would work through the same causal pathway as tobacco plain packaging. The conclusion that a pre-vetting mechanism would not make an equivalent contribution rested on difficulties created by administrative discretion concerning which packages should be allowed on the market, judicial review, and the uncertainties introduced by the possibility of litigation, among others (paras. $7.1678,7.1680)$.

The Panel's bottom line, in concluding that none of the first three of the alternatives have equivalent effect, was that they would not:

address the effect of branding on the appeal of tobacco products, on the effectiveness of GHWs, and on the ability of retail packaging of tobacco products to mislead consumers about the harmful effects of smoking or using tobacco products. This leaves one aspect of Australia's multifaceted approach to tobacco control entirely or partly unaddressed.. ${ }^{31}$

Thus, the fact that the tobacco plain packaging measures are, by design, part of a comprehensive and complementary policy (para. 7.1729) led the Panel to expect the proposed alternatives to work through similar causal mechanisms to the tobacco plain packaging measures. Removing the plain packaging measures without substituting a policy that addressed the different aspects of the current approach would create, in the Panel's opinion, a "regulatory gap" (para. 7.1728).

That does not mean that technical regulations may be simply inoculated from challenge under TBT Article 2.2 by creating comprehensive and complementary policies. As shown in this case and Brazil - Retreaded Tyres, respondents must demonstrate genuine attempts to address real-world problems, against the backdrop of an understanding by WTO Panels and the Appellate Body that

\footnotetext{
${ }^{30}$ Panel Reports, Australia - Tobacco Plain Packaging, para. 7.1526, citing Appellate Body Reports, US - COOL (Article 21.5 - Canada and Mexico), para. 5.216 fn 660.

${ }^{31}$ Panel Reports, Australia - Tobacco Plain Packaging, para. 7.1721
} 
certain types of problems (including certain environmental and health problems) must be addressed through multiple avenues. For example, the FCTC includes in Article 4.4 among its guiding principles the need for "[c]omprehensive multisectoral measures and responses to reduce consumption of all tobacco products at the national, regional and international levels" to prevent "diseases, premature disability and mortality". Article 5.1, in turn, imposes on FCTC parties a general obligation to implement "comprehensive multisectoral national tobacco control strategies, plans and programmes".

Given that the Panel arguably equated the plain packaging measures' contribution to their objective with their level of trade-restrictiveness, the Panel might have avoided the complex arguments by which it arrived at the conclusion that Australia's plain packaging measures were justified under TBT Article 2.2. If the measures restrict trade to the extent that they contribute to their objective by reducing sales, then under the comparative analysis, it is difficult to see how any conceivable alternative measure could contribute more to the objective while being less trade-restrictive. This conclusion could be stated succinctly in place of over 100 pages in the Panel Reports. However, even if the Panel's conflation of contribution and trade-restrictiveness is justified in this particular case, this approach might be inappropriately adopted in future cases in which the underlying facts are quite different. The Panel's extensive examination of the proposed alternatives could assist in avoiding this kind of inappropriate transferral of reasoning. The Panel would also have had in mind the need to satisfy the Appellate Body with a detailed assessment of the facts and law to avoid being overturned.

\section{WEIGHING AND BALANCING UNDER THE TBT, TRIPS AND OTHER WTO AGREEMENTS}

As foreshadowed above, the Panel relied on aspects of its relational and comparative analysis regarding trade-restrictiveness under TBT Article 2.2 in its subsequent assessment of the complainants' claims of breach of Article 20 of TRIPS. Article 20 precludes WTO Members from "unjustifiably encumber[ing] by special requirements" the "use of a trademark in the course of trade". Examples of such special requirements mentioned in the provision include "use in a special form or use in a manner detrimental to its capability to distinguish the goods or services of one undertaking from those of other undertakings". As the Panel found that Australia's measures do encumber the use of trademarks in the course of trade within the meaning of TRIPS Article 20, the dispute on this provision focused on whether the measures "unjustifiably" encumbered such trademark use. The Panel found that this question revolves around whether the use of a trademark is encumbered "in a manner that lacks a justification or reason that is sufficient to support the resulting encumbrance" (para. 7.2395).

In identifying what might be suitable justifications for encumbering the use of a trademark in the course of trade, the Panel looked to Articles 7 (Objectives) and 8 (Principles) of TRIPS as relevant context pursuant to VCLT Article 31(1), as well as the preamble to TRIPS in connection with its object and purpose. The Panel supported this approach by reference to paragraph 5 of the Doha 
Declaration, ${ }^{32}$ which it characterised a "subsequent agreement" within the meaning of VCLT Article 31(3)(a). Moreover, the Panel considered that "the use of identical or different terms in different provisions of the covered agreements may provide relevant context and shed light on the meaning to be given to each of them in their respective contexts" (para. 7.2415). In this regard, the Panel contrasted the use of the word "unjustifiably" in TRIPS Article 20 with the use of the word "necessary" in other TRIPS provisions and with the word "unjustifiable" in the chapeau of GATT Article XX.

The Panel concluded that it needed to consider three factors in determining whether the use of a trademark was being unjustifiably encumbered: the nature and extent of the encumbrance; the reasons for the special requirements, including any societal interests; and whether these reasons provide sufficient support for the encumbrance (para. 7.2431). The Panel declined to state how these factors should be "weighted and balanced", maintaining that a case-by-case analysis was required. Nevertheless, in applying these factors to the case at hand, the Panel adopted reasoning quite similar to that applied under TBT Article 2.2 and, indeed, the general exceptions in Article XX of GATT and Article XIV of the General Agreement on Trade in Services.

For example, the Panel rejected the complainants' contention that a prohibition on use of a trademark necessarily unjustifiably encumbers that use, drawing an analogy with the Appellate Body's reasoning in Brazil - Retreaded Tyres that a measure as trade-restrictive as an import ban might nevertheless be necessary within the meaning of GATT Article XX(b). ${ }^{33}$ In relation to the nature and extent of the encumbrance imposed by plain packaging, the Panel referred to the earlier evidence analysed under TBT Article 2.2 with respect to the impact on prices and alleged downtrading. In relation to Australia's reasons for plain packaging, the Panel relied on Australia's objective as already identified for the purpose of the claims under TBT Article 2.2, as well as taking note of the preamble to the FCTC. In relation to the third factor, which essentially calls for the Panel to weigh the other two factors against each other, the Panel referred again to certain FCTC guidelines as well as its analysis of the four proposed alternatives already addressed under TBT Article 2.2. The Panel concluded overall that it was "not persuaded that the complainants have demonstrated that Australia has acted beyond the bounds of the latitude available to it under Article 20 to choose an appropriate policy intervention to address its public health concerns in relation to tobacco products" (para. 7.2604).

The extent of the Panel's reliance in its TRIPS Article 20 analysis on its earlier TBT Article 2.2 analysis could be concerning to some Members given the different wording and nature of the two provisions. Similarly, the extent of overlap between the reasoning and tests under these provisions with that under GATT Article XX and GATS Article XIV might suggest a converging of the caselaw, leaving more to the discretion of Panels and the Appellate Body in how they weigh and

\footnotetext{
${ }^{32}$ Declaration on the TRIPS Agreement and Public Health, WTO Doc WT/MIN(01)/Dec/2 (14 November 2001).

${ }_{33}$ Panel Reports, Australia - Tobacco Plain Packaging, para. 7.2442, quoting Appellate Body Report, Brazil Retreaded Tyres, paras. 150-151.
} 
balance relevant factors, notwithstanding their different roles in different WTO agreements. These different provisions form part of the same treaty (the WTO agreements), and so in that sense they do provide relevant context for interpretative purposes. ${ }^{34}$ However, the latter two provisions are exceptions, whereas the former two are positive obligations, which affects the burden of proof, as the Appellate Body has recognised. ${ }^{35}$ And as the Panel stated, unjustifiably is not the same as unjustifiable or unnecessary.

\section{CONCLUSION}

For Cuba and Indonesia, these adopted Panel Reports represent the final word in their dispute over Australia's tobacco plain packaging measures. According to the Panel in these reports, traderestrictiveness - at least for the purposes of TBT Article 2.2-means a limiting effect on international trade with one or more WTO Members. Despite the dearth of country-specific evidence before it, the Panel found that Australia's measures do have a limiting effect on trade within these terms. The evidence was inconclusive as regards the impact of the measures on the value of trade and on competitive opportunities. Ultimately, notwithstanding considerable questions surrounding the impact of the measures on the Australian market, the Panel found that the measures are trade-restrictive within the meaning of TBT Article 2.2 because, by reducing the use of tobacco products, they reduce the volume of imported products on the market.

But the Panel's analysis under Article 2.2 continued, given that mere trade restriction is insufficient to show a breach of that provision. The Panel found that none of the four alternatives proposed by the complainants would have made an equivalent contribution to Australia's health objective while restricting trade to a lesser degree. This conclusion under Article 2.2 might arise for any effective and non-discriminatory measure that restricts trade by reducing consumption of a socially 'bad' or undesirable product, whether from the perspective of promoting public health or some other nontrade objective such as preserving the environment. In such circumstances, a WTO dispute under Article 2.2 will be likely to focus on how effective the measure really is in contributing to its nontrade objective. If it necessarily restricts trade in contributing to that objective (for example, because the product is largely or wholly imported), a panel will likely conclude that it is traderestrictive but no more so than necessary.

The Appellate Body Reports in the continuing disputes brought by the Dominican Republic and Honduras are likely to explore in particular the Panel's reasoning under TBT Article 2.2 as well as its findings under TRIPS Article 20 and the correct approach to weighing and balancing under each. Any further refinements are likely to colour for the future the Panel Reports in the disputes with Cuba and Indonesia, even though from a legal perspective those reports are binding on the parties in those disputes. If the Appellate Body agreed with Australia that the trade-restrictiveness of a measure under TBT Article 2.2 depends on the extent to which it restricts trade with all WTO Members, this would not necessarily mean that Australia's measures don't restrict trade, since the

\footnotetext{
${ }^{34}$ Ibid para. 5.329.

${ }^{35}$ See, eg, Appellate Body Reports, US - COOL (Article 21.5 - Canada and Mexico), para. 5.333.
} 
evidence on a reduction in imports was largely based on imports from all sources anyway. If the Appellate Body found the measures not trade-restrictive because they reduce consumption on a non-discriminatory basis, this would end the analysis before needing to turn to the question of less trade-restrictive alternatives. However, such a conclusion might call into question the need for separate provisions on discrimination (TBT Article 2.1) and trade-restrictiveness (TBT Article 2.2). The relationship between and depths of these two provisions are proving perhaps more complex than the drafters realised or intended. 


\section{References}

Campaign for Tobacco-Free Kids (2018), 'The Global Cigarette Industry,' Available from https://www.tobaccofreekids.org/assets/global/pdfs/en/Global Cigarette Industry pdf.pdf

Crowley M. and Howse R. (2014), 'Tuna - Dolphin II: A Legal and Economic Analysis of the Appellate Body Report', World Trade Review, 13(2): 321-355.

Liberman J. (2013), 'Plainly Constitutional: The Upholding of Plain Tobacco Packaging by the High Court of Australia', American Journal of Law and Medicine, 39: 361-381.

Mavroidis P. and Saggi K. (2014), 'What is Not So Cool about US - COOL Regulations? A Critical Analysis of the Appellate Body's Ruling on US-COOL', World Trade Review, 13(2): 299-320.

Scollo, M. and Bayly, M. (2019a), '10.3 The manufacturing and wholesaling industry in Australia-major international companies.' In Scollo, MM and Winstanley, MH [editors]. Tobacco in Australia: Facts and issues. Melbourne: Cancer Council Victoria; Available from http://www.tobaccoinaustralia.org.au/chapter-10-tobacco-industry/10-3-the-

manufacturing-and-wholesaling-industry-in-australia

Scollo, M, and Bayly, M. (2019b), '10.6 Retail value and volume of the Australian tobacco market.' In Scollo, MM and Winstanley, MH [editors]. Tobacco in Australia: Facts and issues. Melbourne: Cancer Council Victoria. from http://www.tobaccoinaustralia.org.au/chapter-10-tobacco-industry/10-6-retail-value-andvolume-of-the-australian-tobacco-market

Voon T. (2015), 'Exploring the Meaning of Trade-Restrictiveness in the WTO', World Trade Review, 14(3): 451-477.

Voon T. (2019), 'Third Strike: The WTO Panel Reports Upholding Australia's Tobacco Plain Packaging Scheme', Journal of World Investment \& Trade, 20: 146-184.

Zhou S., Liberman J. and Ricafort E. (2018), 'The Impact of the WHO Framework Convention on Tobacco Control in Defending Legal Challenges to Tobacco Control Measures', Tobacco Control doi:10.1136/tobaccocontrol-2018-054329. 